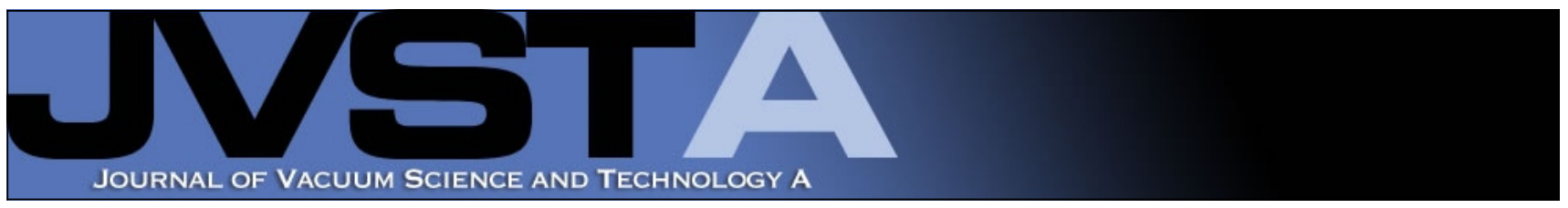

\title{
Formation and transfer of GaAsN nanostructure layers
}

R. R. Collino, A. W. Wood, N. M. Estrada, B. B. Dick, H. W. Ro et al.

Citation: J. Vac. Sci. Technol. A 29, 060601 (2011); doi: 10.1116/1.3630120

View online: http://dx.doi.org/10.1116/1.3630120

View Table of Contents: http://avspublications.org/resource/1/JVTAD6/v29/i6

Published by the AVS: Science \& Technology of Materials, Interfaces, and Processing

\section{Related Articles}

Analyzing pattern retention for multilayer focused ion beam induced quantum dot structures J. Vac. Sci. Technol. B 31, 031208 (2013)

Review of radiation damage in GaN-based materials and devices

J. Vac. Sci. Technol. A 31, 050801 (2013)

Type-II InAs/GaSb strained layer superlattices grown on GaSb (111)B substrate

J. Vac. Sci. Technol. B 31, 03C123 (2013)

Polarity control and transport properties of Mg-doped (0001) InN by plasma-assisted molecular beam epitaxy J. Vac. Sci. Technol. A 31, 031504 (2013)

Growth and characterization of GaP/GaNP core/shell nanowires

J. Vac. Sci. Technol. B 31, 03C110 (2013)

\section{Additional information on J. Vac. Sci. Technol. A}

Journal Homepage: http://avspublications.org/jvsta

Journal Information: http://avspublications.org/jvsta/about/about_the_journal

Top downloads: http://avspublications.org/jvsta/top_20_most_downloaded

Information for Authors: http://avspublications.org/jvsta/authors/information_for_contributors

\section{ADVERTISEMENT}

\section{Instruments for advanced science}
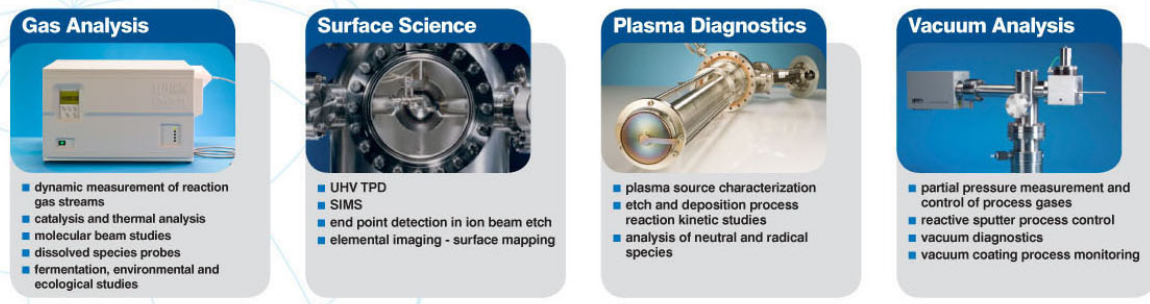

contact Hiden Analytical for further details

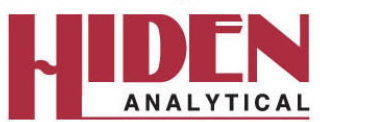

info@hideninc.com

www.HidenAnalytical.com

CLICK to view our product catalogue 


\title{
LETTERS
}

\section{Formation and transfer of GaAsN nanostructure layers}

\author{
R. R. Collino ${ }^{\text {a) }}$ \\ Department of Mechanical Engineering, University of Michigan, Ann Arbor, Michigan 48109-2125, \\ USA and Department of Materials Science and Engineering, University of Michigan, Ann Arbor, \\ Michigan 48109-2136, USA
}

A. W. Wood

Department of Materials Science and Engineering, University of Michigan, Ann Arbor, Michigan 48109-2136, USA and Department of Physics, University of Michigan, Ann Arbor, Michigan 48109-1040, USA

N. M. Estrada and B. B. Dick

Department of Materials Science and Engineering, University of Michigan, Ann Arbor, Michigan 48109-2136, USA

H. W. Ro and C. L. Soles

Polymers Division, National Institute of Standards and Technology, Gaithersburg, Maryland 20899, USA

Y. Q. Wang

Materials Science and Technology Division, Los Alamos National Laboratory, Los Alamos, New Mexico 87545, USA

M. D. Thouless ${ }^{\text {b) }}$

Department of Mechanical Engineering, University of Michigan, Ann Arbor, Michigan 48109-2125, USA and Department of Materials Science and Engineering, University of Michigan, Ann Arbor, Michigan 48109-2136, USA

R. S. Goldman ${ }^{\text {) }}$

Department of Materials Science and Engineering, University of Michigan, Ann Arbor, Michigan 48109-2136, USA and Department of Physics, University of Michigan, Ann Arbor, Michigan 48109-1040, USA

(Received 13 December 2010; accepted 8 August 2011; published 27 September 2011)

The authors report the simultaneous formation and transfer of GaAsN nanostructure layers to alternative substrates, a process termed "ion-cut synthesis." Ion-cut synthesis is induced by nitrogen ion implantation into GaAs (GaAs:N), followed by spin-on-glass (SOG) mediated wafer bonding and high temperature rapid thermal annealing (RTA). Due to the low ion-matrix diffusivity of GaAs:N, RTA induces the formation of both nanostructures and gas bubbles. The gas bubble pressure induces the formation and propagation of cracks, resulting in transfer of the nanostructured layer. The authors discuss the critical role of the physical properties and the thicknesses of the substrates and the SOG layer to the achievement of ion-cut synthesis. (C) 2011 American Vacuum Society. [DOI: 10.1116/1.3630120]

\section{INTRODUCTION}

During the past decade, ion implantation followed by thermal annealing has emerged as a promising approach for the formation of gas bubbles and/or nanocrystalline phases. For implantation of light ions into semiconductors, the formation and coalescence of gas bubbles has led to the development of an approach for heterogeneous materials integration, termed "ion-cut" or Smart Cut ${ }^{\mathrm{TM}}{ }^{1}$ The ion-cut process involves high-energy ion implantation into a donor substrate which is then bonded to another substrate. Subsequent thermal annealing leads to the formation and coalescence of gas bubbles, resulting in the fracture of original

\footnotetext{
a) Present address: Department of Mechanical Engineering, University of California, Santa Barbara, Santa Barbara, CA 93106-5070.

b)Electronic mail: thouless@umich.edu

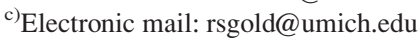

substrate. This surface layer remains bonded to the new substrate, and the original substrate may be re-used for additional thin film processing. Ion-cut was first demonstrated using $\mathrm{H}$ ions to transfer crystalline silicon to an amorphous oxide ${ }^{1}$ it was subsequently expanded to other light ions such as $\mathrm{He}$ (Ref. 2) and $\mathrm{D},{ }^{3}$ as well as $\mathrm{H} / \mathrm{He}$ co-implantation., To date, ion-cut has been used to transfer InP to glass, ${ }^{6} \mathrm{SiGe}$ to $\mathrm{Si}^{7,8} \mathrm{SiC}$ to $\mathrm{Si}$ (Ref. 9) and glass, ${ }^{10} \mathrm{GaSb}$ to glass ${ }^{11}$ and GaAs, ${ }^{12} \mathrm{Ge}$ to $\mathrm{Si},{ }^{13}$ garnet to $\mathrm{Si}, \mathrm{InP}$, and $\mathrm{GaAs},{ }^{14}$ and complex oxides such as $\mathrm{SrTiO}_{3}$ to glass ${ }^{15}$ and $\mathrm{LiNbO}_{3}$ to silicon. ${ }^{16}$ In these light-ion, high-diffusivity systems, bubble formation and layer transfer have been reported to occur within relatively low dose ${ }^{17}\left(3 \times 10^{16}-1 \times 10^{17} \mathrm{~cm}^{-2}\right)$ and temperature ${ }^{18}\left(400-600^{\circ} \mathrm{C}\right)$ windows.

It is also possible to precipitate nanocrystalline phases using ion implantation followed by thermal annealing. For example, precipitation of $\mathrm{Si}$ nanocrystals in $\mathrm{Si}: \mathrm{H}$ (Ref. 19) and $\mathrm{SiO}_{2}: \mathrm{He}$ 
(Ref. 20), GaN nanocrystals in GaAs:N (Refs. 21-23), and InN nanocrystals in InAs:N (Ref. 24) have been reported. In light-ion, high-diffusivity systems, such as $\mathrm{Si}: \mathrm{H}$, the formation of nanocrystals requires high ion doses $\left(1-3 \times 10^{17} \mathrm{~cm}^{-2}\right)$ and high annealing temperatures $\left(600-800{ }^{\circ} \mathrm{C}\right),{ }^{19}$ conditions which are very different from those needed for bubble formation and layer transfer. For both nanocrystals and gas bubbles to be observed simultaneously, the gas bubbles need to be stable at the high temperatures required for nanocrystal formation. Indeed, the high diffusivity of $\mathrm{H}$ in $\mathrm{Si}: \mathrm{H}$ may preclude the formation of gas bubbles at the high temperatures required for nanocrystal formation. Thus, it is not surprising that the simultaneous formation and transfer of a nanostructured layer has not been reported to date.

On the other hand, in a system with low ion-matrix diffusivity, the formation of both nanocrystals and bubbles at high temperature has been reported. For example, in GaAs: N, precipitation of both nitrogen gas bubbles and nitride nanocrystals has been observed. ${ }^{23}$ The GaAsN nanostructures consisted of nanometer-sized GaN-rich crystallites in an apparently amorphous matrix, which we will refer to as a "GaAs:N nanocomposite." Photoluminescence and cathodoluminescence spectroscopy showed significant emission in the nearinfrared range, apparently related to those nanostructures. ${ }^{21,22}$ In addition, due to the observed formation of both nanocrystals and gas bubbles following high-temperature annealing of GaAs:N, the simultaneous nanostructuring and layer transfer of GaAs: $\mathrm{N}$ was proposed, ${ }^{23}$ but not yet achieved.

In this letter, we report on the development and demonstration of a new technique for the simultaneous nanostructuring and layer transfer of a GaAs:N film, termed "ion-cut synthesis." Ion-cut synthesis is accomplished via $\mathrm{N}$-ion implantation in GaAs, followed by spin-on glass (SOG)mediated wafer bonding and rapid-thermal annealing (RTA). Due to the low ion-matrix diffusivity of GaAs:N, hightemperature RTA induces the formation of both nanocrystals and gas bubbles. Since the gas bubble pressure induces the formation and propagation of cracks, simultaneous nanostructuring and layer transfer are accomplished. Finally, we show that the achievement of ion-cut synthesis depends on the physical properties and thickness of the substrates and the SOG layer.

\section{EXPERIMENTAL METHODS}

GaAs films (undoped or Si-doped, $\sim 1 \mu \mathrm{m}$ thick) were grown by molecular-beam epitaxy on (001) GaAs. These films were implanted with $100 \mathrm{keV} \mathrm{N}{ }^{+}$at a fluence of $5 \times 10^{17} \mathrm{~cm}^{-2}$, as described in earlier reports. ${ }^{23,25}$ To minimize ion channeling, a $\sim 7^{\circ}$ ion beam angle of incidence with respect to the sample surface normal was used. During implantation, the GaAs substrate temperature was maintained at $-196{ }^{\circ} \mathrm{C}$, as measured by a thermocouple attached to the sample holder. In preparation for bonding, the $\mathrm{N}$ implanted $\mathrm{GaAs}$ and polycrystalline $\mathrm{Al}_{2} \mathrm{O}_{3}$ and AlN substrates were cleaned with a sequence of de-ionized (DI) water, acetone, and methanol, followed by a final DI water rinse. Immediately prior to bonding, SOG layers consisting of either a commercial polymethylsilsesquioxane (PMSSQ) SOG (Filmtronics FG65), or a methyltrimethoxysilane-1,2bis(triethoxysilyl)ethane (MTMS-BTSE) SOG synthesized at NIST, ${ }^{26}$ were spin-coated onto the ceramic substrates. In the case of the PMSSQ films, a thickness of $1000 \mathrm{~nm}$ was achieved by spin-coating the solution at $3500 \mathrm{rpm}$ for $30 \mathrm{~s}$. To achieve a thickness of $200 \mathrm{~nm}$, the solution was diluted with $25 \%$ ethyl acetate and spun at $3000 \mathrm{rpm}$ for 20 s. 200 $\mathrm{nm}$ MTMS-BTSE films were obtained by spin-coating at $1200 \mathrm{rpm}$ for $15 \mathrm{~s}$. Following these surface preparations, $\sim 3$ $\mathrm{mm} \times 3 \mathrm{~mm}$ GaAs:N pieces $(\sim 600 \mu \mathrm{m}$ thick $)$ and $\sim 1 \mathrm{~cm}^{2}$ ceramic substrates $(\sim 100 \mu$ m thick $)$ were pressed together (at room temperature) with tweezers, a process which we will refer to as "joining." The final step consisted of RTA in $\mathrm{N}_{2}$ gas for $30 \mathrm{~s}$ at $800{ }^{\circ} \mathrm{C}$, leading to nanocrystal formation, solidification of the SOG, and layer transfer.

The morphology and microstructure of the GaAs:N layers were examined by scanning-electron microscopy (SEM), atomic force microscopy (AFM), and transmission-electron microscopy (TEM). The SEM studies of the blistered surfaces were carried out in a FEI Nova Nanolab operating at $5 \mathrm{kV}$ with a beam current of $40 \mathrm{pA}$. To image the GaAs:N nanocomposite transferred to insulating substrates, lowvacuum ( $\sim 0.8$ Torr) SEM was carried out in a Quanta $2003 \mathrm{D}$ operating at 15 or $20 \mathrm{kV}$, with a beam current of $\sim 0.3 \mathrm{nA}$. Tapping-mode AFM was performed in a Digital Instruments Nanoscope IIIA using etched Si tips. TEM was carried out in a JEOL 3011 high-resolution TEM operating at $300 \mathrm{kV}$. For selected-area electron diffraction (SAED) studies, a $\sim 130 \mathrm{~nm}$ diameter aperture was used.

The TEM specimens were prepared by the focused ion beam (FIB) lift-out technique described in Ref. 27. The FIB lift-out process was carried out in FEI Nova Nanolab and Quanta 200 3D dual-beam (SEM + FIB) systems. To minimize surface charging of the SOG and ceramic layers during SEM imaging, the top surfaces of each layer-transfer sample were sputter-coated with $\sim 50 \AA$ of AuPd or C. To protect the GaAs: $\mathrm{N}$ surface from Ga ion damage during the FIB liftout process, $\sim 2 \mu \mathrm{m} \times 15 \mu \mathrm{m}$ regions of the surface were coated with $\sim 200 \mathrm{~nm}$ of electron-beam-assisted chemicalvapor-deposited (CVD) Pt followed by $\sim 2 \mu \mathrm{m}$ of ion-beamassisted CVD Pt. A $5.0 \mathrm{nA} \mathrm{Ga}{ }^{+}$beam operating at $30 \mathrm{kV}$ was then used to mill away the material outside the Pt coated region, leaving a "FIB lift-out" TEM specimen. Using a micro-manipulator needle, the TEM specimen was then attached to a $\mathrm{Cu}$ grid with posts for lift-out sample placement. Finally, to produce a region that was sufficiently thin for electron transparency, FIB-milling steps were performed at $20 \mathrm{kV}, 0.38 \mathrm{nA} ; 10 \mathrm{kV}, 0.12 \mathrm{nA}$; and $10 \mathrm{kV}, 50 \mathrm{pA}$.

\section{MATERIALS SELECTION}

The first step towards the simultaneous formation and transfer of a GaAs: $\mathrm{N}$ nanocomposite layer involves the identification of suitable alternative substrates and bonding layers. Although SOGs have been employed as an intermediate layer for wafer bonding and layer transfer of dissimilar materials, ${ }^{28,29}$ the application of SOG-mediated transfer to this 
new process is particularly challenging due to the high temperatures (RTA $>750{ }^{\circ} \mathrm{C}$ ) required for nanostructure formation. For this purpose, we compare the driving force for delamination or fracture (the energy release rate, $\mathcal{G}$ ) with its corresponding materials property that governs failure (the toughness, $\Gamma$ ), aiming to maintain $\mathcal{G}<\Gamma$. Here, $\mathcal{G}$ is proportional to a thermal expansion coefficient (TEC) mismatch and thickness, but independent of the in-plane dimensions of the wafer(s),${ }^{30}$ as follows:

$$
\mathcal{G} \propto[\Delta \alpha(T)]^{2} \cdot h .
$$

We first consider the step of joining the implanted GaAs wafer to a ceramic substrate, as shown in Fig. 1(a), neglecting the thickness of the viscous SOG layer. We then consider the step of high-temperature annealing, at which point much of the original substrate is removed (via layer splitting), as shown in Fig. 1(b), leaving the transferred GaAsN nanostructure layer with a thickness similar to that of the solidified SOG bonding layer.

Following the initial joining of the implanted GaAs and ceramic substrate, as shown in Fig. 1(a), subsequent excursions between RT and the RTA temperature result in an increased $\mathcal{G}$. Since the SOG thickness $(O(100 \mathrm{~nm}))$ is much less than those of the substrates $(O(100 \mu \mathrm{m}))$, the contribution of the bonding
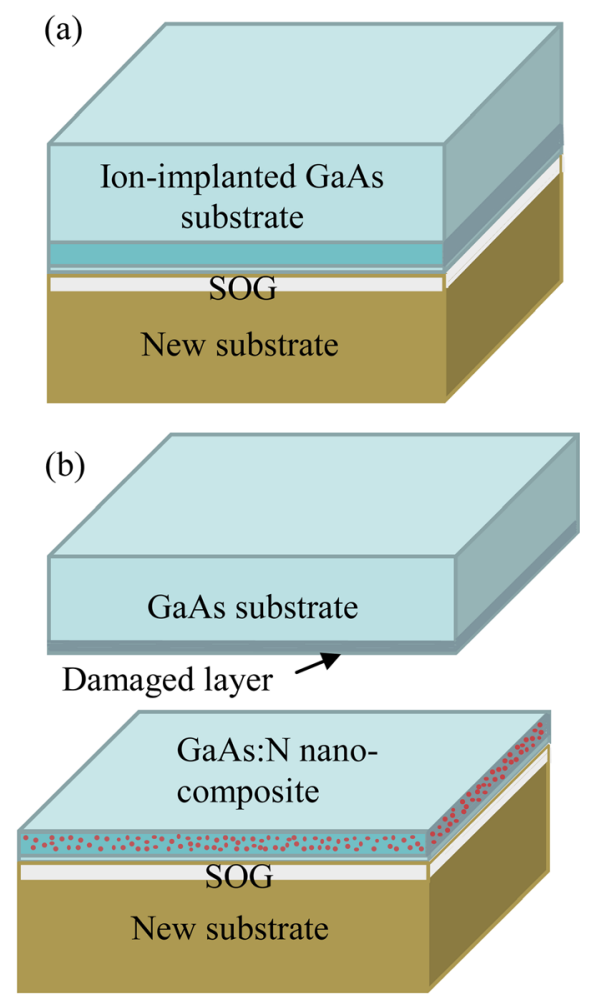

FIG. 1. (Color online) Schematic of nanocomposite synthesis and layer transfer. (a) An ion-implanted GaAs substrate is bonded to a new substrate using a spin-on glass layer. (b) Following thermal annealing, GaN nanocrystals nucleate in the GaAs matrix, forming a GaAs:N nanocomposite layer. Simultaneously, nitrogen gas bubbles lead to interfacial cracking between the GaAs:N nanocomposite layer and GaAs substrate, inducing separation from the GaAs substrate. In principle, the damaged layer of the "parent" GaAs substrate may be polished off and the parent substrate recycled for further processing. layer to $\mathcal{G}$ is neglected. For each GaAs/ceramic substrate pair, $\mathcal{G}$ is calculated using Eq. 1 , with $\Delta \alpha=\Delta \alpha_{\text {joined }}$, the difference in the TECs of the two substrates, and $h=h_{\text {ceramic }}$, the thickness of the ceramic substrate. ${ }^{31}$ To minimize $\mathcal{G}$, substrates with TECs similar to that of $\mathrm{GaAs}$ were chosen, namely $\mathrm{Al}_{2} \mathrm{O}_{3}$ and AlN. We note that $\alpha_{\mathrm{GaAs}} \approx 5.7 \times 10^{-6}{ }^{\circ} \mathrm{C}^{-1}, \alpha_{\mathrm{Al}_{2} \mathrm{O}_{3}} \approx$ $5.4 \times 10^{-6}{ }^{\circ} \mathrm{C}^{-1}$, and $\alpha_{\mathrm{AIN}} \approx 4.0 \times 10^{-6}{ }^{\circ} \mathrm{C}^{-1}$.

Following the high-T annealing step, shown in Fig. 1(b), the original GaAs substrate is removed by layer splitting, and the remaining bonding and transferred nanocomposite layers, with similar thicknesses, are both expected to contribute to $\mathcal{G}$. In this case, the relevant toughness is that of the solidified bonding layer, $\Gamma_{\text {SOG }}$. Neglecting the transferred layer, $\mathcal{G}$ is then expressed as in Eq. (1), with $\Delta \alpha_{\text {annealed }}=\alpha_{\text {ceramic }}$ $-\alpha_{\mathrm{SOG}}$ and $h=h_{\mathrm{SOG}}$, the thickness of the solidified bonding layer.

First, we consider the influence of $h_{\text {SOG }}$ using a commercial MSSQ SOG (Filmtronics FG65). ${ }^{32}$ The $\sim 1000 \mathrm{~nm}(\sim 200$ $\mathrm{nm}$ ) thick SOG layers are referred to as "thick" ("thin") bonding layers. The surface morphology of the transferred layer achieved with the thick bonding layer is shown in the SEM image in Fig. 2(a). The transferred GaAs:N layers contain channel cracks that apparently extend into the bonding layer, as suggested by the AFM image and corresponding line-cut in Fig. 2(b). The presence of channel cracks suggests an overall tensile stress in the bonding and transferred layers. The rms roughness $\left(R_{\mathrm{rms}}\right)$ of the transferred layer is $190 \pm 30 \mathrm{~nm}$, as determined from areas similar to that shown by the dashedline box in Fig. 2(b) (i.e., excluding channel cracks).

For a "thin" SOG layer, as shown in Fig. 2(c), channelcracking is not apparent. In addition, as shown in the AFM image in Fig. 2(d), the $R_{\mathrm{rms}}$ of the transferred area is $60 \pm 20$ $\mathrm{nm}$, roughly half that of the cracked layer in Fig. 2(b). The AFM image also reveals "hole" defects [highlighted with dashed circles in Fig. 2(d)]. The depths of these defects are on the order of the transferred film thickness, and their diameters are similar to those of the circular blisters observed in unbonded layers. ${ }^{25}$ Thus, it is likely that these defects are due to the formation of blisters and/or voids in localized areas with insufficient bonding.

We also examined the influence of $\Delta \alpha_{\text {annealed }}$, which is equal to $\alpha_{\text {ceramic }}-\alpha_{\text {SOG }}$, via SOG with a TEC similar to those of the ceramic substrates. For this purpose, we used a MTMS-BTSE copolymer based SOG, which has been observed to exhibit a composition-dependent TEC. ${ }^{26}$ A TEC of $\sim 6 \times 10^{-6}{ }^{\circ} \mathrm{C}^{-1}$ is feasible with $50 \mathrm{~mol}$. \% BTSE in the SOG formulation synthesized from pure MTMS. In particular, the TEC of the copolymer decreases with increasing BTSE concentration, with a BTSE concentration of $\sim 50 \%$ which is most desirable for TEC-matching of the SOG film to the ceramic substrates.

\section{SYNTHESIS AND TRANSFER OF GaAs:N LAYERS}

Using the MTMS-BTSE SOG, we achieved the formation and transfer of nanostructured GaAs: $\mathrm{N}$ layers to both $\mathrm{Al}_{2} \mathrm{O}_{3}$ and AlN substrates. For example, the surface of the layer 

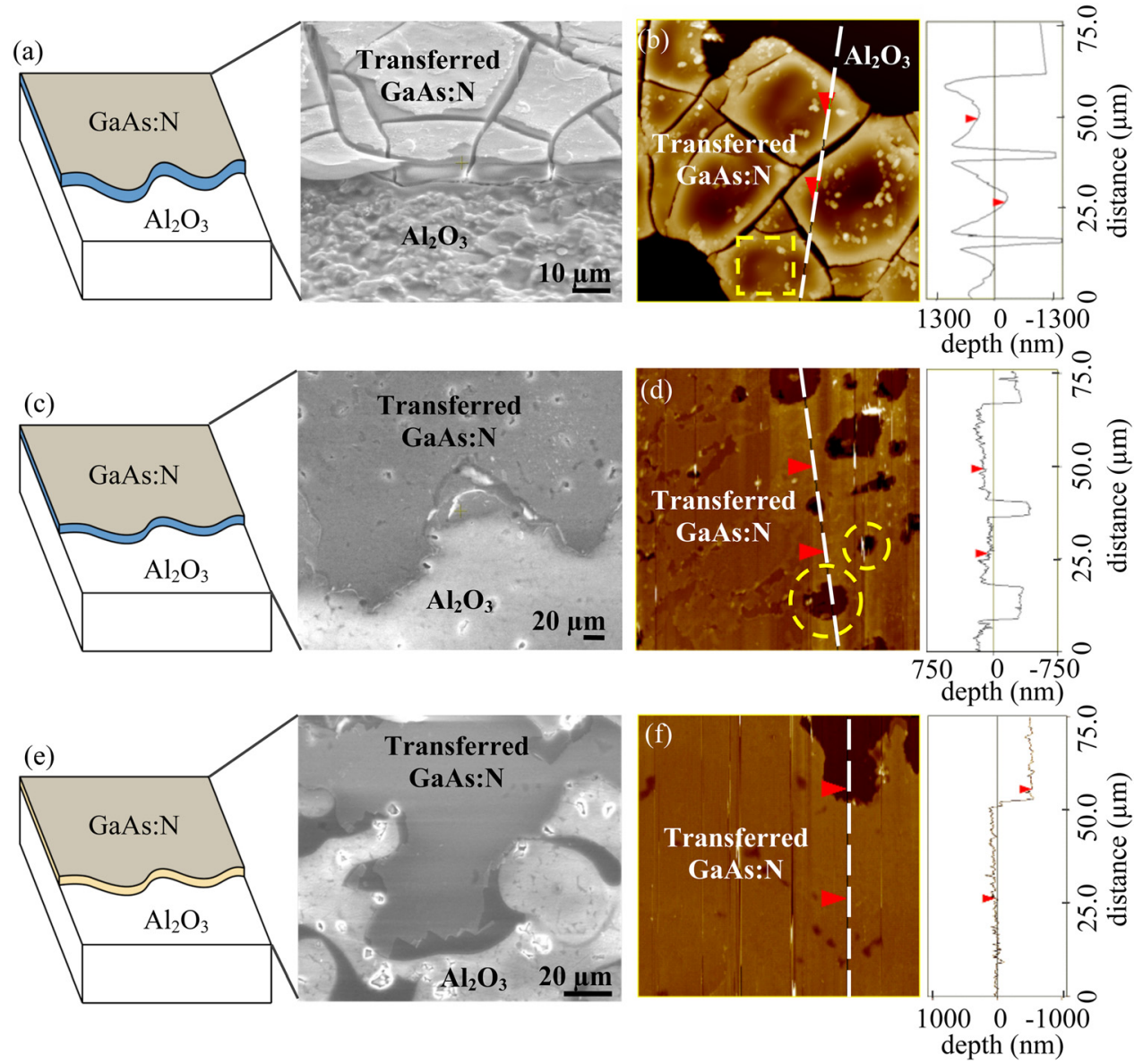

FIG. 2. (Color online) Improved transfer quality of GaAs:N nanocomposite layers with various bonding conditions. SEM and AFM images of GaAs:N layers transferred to alumina with bonding layers consisting of (a) and (b) $\sim 1 \mu \mathrm{m}$ "thick" PMSSQ SOG, (c) and (d) 200 nm "thin" PMSSQ SOG, and (e) and (f) $\sim 200 \mathrm{~nm}$ "thin" BTSE-MTMS SOG. The SEM image of the surface of the transferred layer bonded with thick PMSSQ in (a) reveals surface "channel" cracks. As shown in the AFM image and corresponding line-cut in (b), these cracks penetrate through the $\sim 200 \mathrm{~nm}$ thick transferred layer to the substrate. A comparison of the SEM images for the "thick" and "thin" PMSSQ SOG layers in (a) and (c) reveals that the roughness of the transferred layer is reduced by decreasing the thickness of the PMSSQ SOG layer. However, the AFM image and corresponding line-cut for the "thin" PMSSQ SOG in (d) reveals pit defects (highlighted by dashed circles) with depths approximately equal to the transferred layer thickness, suggesting that localized blister formation occurs instead of layer transfer, possibly due to the formation and spalling of blisters in localized areas with insufficient bonding. For the thermally-matched BTSE-MTMS SOG, these defects are apparently eliminated, as shown by the SEM and AFM images in (e) and (f).

transferred to $\mathrm{Al}_{2} \mathrm{O}_{3}$, shown in the SEM and AFM micrographs in Figs. 2(e) and 2(f) appears featureless, with $R_{\mathrm{rms}}=20 \pm 5 \mathrm{~nm}$. This $R_{\mathrm{rms}}$ is larger than that of the asimplanted GaAs:N layer $(\sim 3 \mathrm{~nm})$, but it is comparable to the $\sim 15 \mathrm{~nm}$ value reported for the low-temperature transfer of a crystalline GaAs layer to a silicon substrate using plasmaenhanced chemical vapor-deposited $\mathrm{SiO}_{2}$ bonding layers. ${ }^{33}$

Following the joining and annealing of the GaAs: $\mathrm{N}$ layers with $\mathrm{Al}_{2} \mathrm{O}_{3}$ and $\mathrm{AlN}$ substrates, the interfaces and microstructures were examined using cross-sectional transmission-electron microscopy (XTEM), as shown in Fig. 3. Figures 3(a) and 3(c) show bright-field XTEM images of GaAs:N layers transferred to $\mathrm{Al}_{2} \mathrm{O}_{3}$ and $\mathrm{AlN}$ substrates, respectively. In both cases, featureless GaAs: $\mathrm{N}$ nanocomposite/SOG interfaces are apparent. In addition, a featureless SOG/AlN interface is apparent in Fig. 3(c). For both $\mathrm{Al}_{2} \mathrm{O}_{3}$ and $\mathrm{AlN}$ substrates, the transferred layer consists of a $50 \mathrm{~nm}$ polycrystalline GaAs layer plus a $150 \mathrm{~nm}$ nanocomposite layer, with a total thickness of $\sim 200 \mathrm{~nm}$, which corresponds to the depth of maximum $\mathrm{N}$ ion concentration, as will be discussed below.
The occurrence of layer transfer at the depth of maximum $\mathrm{N}$ ion concentration suggests a transfer mechanism based on gas pressure. In earlier studies of ion-beam-synthesized GaAsN nanocomposite layers, surface blister formation was attributed to the RTA-induced formation and coalescence of gas bubbles at the depth of maximum $\mathrm{N}$ ion concentration. ${ }^{21-23,25}$ Indeed, Monte Carlo simulations of $\mathrm{N}$-implantation-induced vacancy and $\mathrm{N}$ depth profiles indicate that nanostructuring and bubble formation occur at depths of 150 and $200 \mathrm{~nm}$, which correspond to the predicted maxima in implantation-induced damage and $\mathrm{N}$ concentration, respectively. ${ }^{34}$ Since delamination occurs at the depth of maximum $\mathrm{N}$ concentration, independent of the constraint imposed by the bonded receiver substrate, it is expected to be governed by the gas pressure in the bubbles/ voids.

Nanostructure formation within the transferred GaAs:N nanocomposite was examined using dark-field (DF) XTEM, SAED, and high-resolution TEM (HRTEM). Figures 3(b) and 3(d) show $\{111\}$ DF XTEM images, with corresponding 

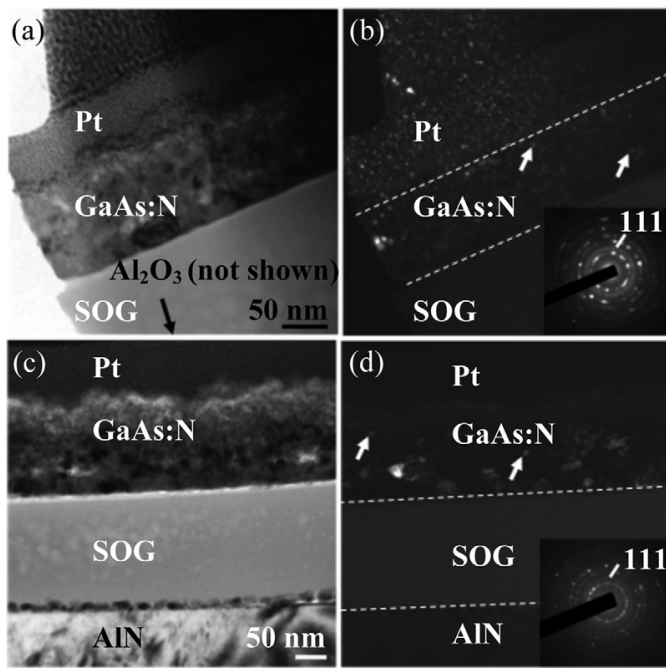

FIG. 3. Nanostructure formation in transferred layers. (a) Bright-field, and (b) dark-field cross-sectional TEM images of GaAs:N layers transferred to an $\mathrm{Al}_{2} \mathrm{O}_{3}$ substrate. (c) Bright-field, and (d) dark-field cross-sectional TEM images of GaAs:N layers transferred to an AlN substrate. In both (b) and (d), corresponding SAED patterns are shown as insets. The SAED patterns of the transferred GaAs:N layers indicate the presence of both zincblende (ZB) GaAs and ZB GaN crystallites. In the dark-field TEM images in (b) and (d), dashed lines indicate smooth interfaces between the GaAs:N nanocrystal and SOG bonding layers. Furthermore, nanometer-size bright features in the GaAs:N layers, indicated by arrows, confirm the formation of nanocrystallites.

SAED patterns as insets, for the GaAs:N layers transferred to $\mathrm{Al}_{2} \mathrm{O}_{3}$ and $\mathrm{AlN}$ substrates, respectively. In both cases, the interfaces between the GaAs:N nanocomposite layer, deposited polycrystalline-Pt layer, and solidified SOG bonding layer are indicated with a dashed line. In addition, the GaAs:N nanocomposite layers contain nanometer-sized bright features, as labeled with arrows in Figs. 3(b) and 3(d), confirming the formation and integration of nanostructured layers with the $\mathrm{Al}_{2} \mathrm{O}_{3}$ and $\mathrm{AlN}$ substrates.

Identification of the nanostructures was performed using SAED and HRTEM collected from the transferred GaAs:N nanocomposite layers. Comparisons of the interplanar spacings measured by SAED and the powder diffraction standards from GaAs and zincblende GaN are shown in Table I. For the GaAs:N nanocomposite layer transferred to the $\mathrm{Al}_{2} \mathrm{O}_{3}$ (AlN) substrate, d-spacings of 3.26, 2.00, and $1.69 \AA$ $(3.26,2.00$, and $1.70 \AA$ ) are observed, within $0.6 \%$ of the $\{111\},\{220\}$, and $\{311\}$ interplanar spacings of GaAs.

TABLE I. Comparison of the interplanar distances measured by selected area electron diffraction of the GaAs:N nanostructured layers with the powder diffraction standards for zincblende (ZB) $\mathrm{GaN}$ and $\mathrm{GaAs}$.

\begin{tabular}{|c|c|c|c|}
\hline \multicolumn{2}{|c|}{ d-spacing $(\AA)$ (experimental) } & \multicolumn{2}{|c|}{ Powder diffraction standard } \\
\hline Fig. 3(b) & Fig. 3(d) & ZB GaN (hkl) & GaAs (hkl) \\
\hline 3.26 & 3.26 & & $3.26(111)$ \\
\hline 2.60 & 2.60 & $2.60(111)$ & \\
\hline 2.00 & 2.00 & & $2.00(220)$ \\
\hline 1.69 & 1.70 & & $1.70(311)$ \\
\hline 1.59 & 1.62 & $1.59(220)$ & \\
\hline
\end{tabular}
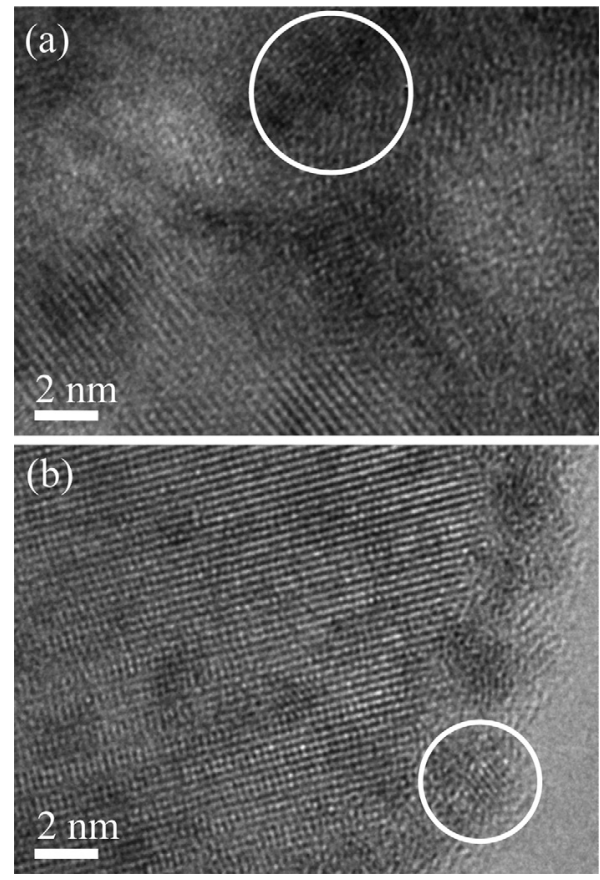

FIG. 4. High-resolution TEM images of transferred nanocomposite layers. Examples of nanometer-sized GaN crystallites are circled for layers transferred to (a) $\mathrm{Al}_{2} \mathrm{O}_{3}$, and (b) AlN substrates.

Additionally, d-spacings of 2.60 and $1.59 \AA$ (2.60 and 1.62 $\AA$ ) are apparent, within $1.9 \%$ of the $\{111\}$ and $\{220\}$ interplanar spacings of $\mathrm{ZB} \mathrm{GaN}$. The nucleation of $\mathrm{ZB} \mathrm{GaN}$ nanocrystals is confirmed by HRTEM studies, which reveal average lattice fringe spacings of 2.02 (Fig. 4(a)) and $2.26 \AA$ (Fig. 4(b)), within $0.5 \%$ of the $\{102\},\{200\}$ interplanar spacings of $\mathrm{ZB} \mathrm{GaN}$.

\section{SUMMARY AND CONCLUSIONS}

In summary, we report a new technique for the simultaneous nanostructuring and layer transfer of a GaAs: $\mathrm{N}$ film, termed "ion-cut synthesis." Ion-cut synthesis is accomplished via N-ion implantation in GaAs, followed by SOGmediated wafer bonding and RTA. Due to the low ionmatrix diffusivity of GaAs:N, high-temperature RTA induces the formation of both nanocrystals and gas bubbles. We show that the successful achievement of ion-cut synthesis depends on the physical properties and thickness of the substrates and bonding layer. Ion-cut synthesis is expected to be useful for the integration of semiconductor nanocomposites with a wide variety of functional alternative substrates.

\section{ACKNOWLEDGMENTS}

RRC and RSG were supported by the Center for Solar and Thermal Energy Conversion, an Energy Frontier Research Center, funded by the U.S. Department of Energy, Office of Science, Office of Basic Energy Sciences under Award No. DE-SC0000957. RRC was also supported in part by graduate research fellowships from the NSF and the Michigan Memorial Phoenix Institute. AWW was supported in part by the AFOSR through the MURI program under Grant No. FA9950-08-1-0340, the U.S. DoD under IC Grant 
No. HM1582-05-1-2027, and CIA Contract No. 20070919714-00. NME and BBD were supported by NSF under Grant No. CMMI-0700301. We gratefully acknowledge the support of the Center for Integrated Nanotechnologies at Los Alamos National Laboratory, as well as the assistance of the staff at the Electron Microscopy and Microanalysis Laboratory, the Lurie Nanofabrication Facility, and the Michigan Ion Beam Laboratory at UM. The ion implanter at MIBL is funded by NSF Grant No. DMR-0520701.

${ }^{1}$ M. Bruel, Electron. Lett. 31, 1201 (1995).

${ }^{2}$ X. Lu, S. K. Iyer, C. Hu, N. W. Cheung, J. Min, Z. Fan, and P. K. Chu, Appl. Phys. Lett. 71, 2767 (1997).

${ }^{3}$ N. Desrosiers and B. Terreault, Appl. Phys. Lett. 89, 151922 (2006).

${ }^{4}$ A. Agarwal, T. E. Haynes, V. C. Venezia, O. W. Holland, and D. J. Eaglesham, Appl. Phys. Lett. 72, 1086 (1998).

${ }^{5}$ P. Nguyen, I. Cayrefourcq, K. K. Bourdelle, A. Boussagol, E. Guiot, N. Ben Mohamed, N. Sousbie, and T. Akatsu, J. Appl. Phys. 97, 083527 (2005).

${ }^{6}$ W. Chen, A. Zhang, P. Chen, J. E. Pulsifer, T. L. Alford, T. F. Kuech, and S. S. Lau, Appl. Phys. Express 2, 022201 (2009).

${ }^{7}$ L. J. Huang, J. O. Chu, D. F. Canaperi, C. P. D’Emic, R. M. Anderson, S. J. Koester, and H.-S. P. Wong, Appl. Phys. Lett. 78, 1267 (2001).

${ }^{8}$ H. Moriceau, F. Fournel, B. Aspar, B. Bataillou, A. Beaumont, C. Morales, A. M. Cartier, S. Pocas, C. Lagahe, E. Jalaguier, A. Soubie, B. Biasse, N. Sousbie, S. Sartori, J. F. Michaud, F. Letertre, O. Raysssac, I. Cayrefourcq, C. Richtarch, N. Daval, C. Aulnette, T. Akatsu, B. Osternaud, B. Ghyselen, and C. Mazure, J. Electron. Mater. 32, 829 (2003).

${ }^{9}$ L. Di Cioccio, F. Letertre, Y. Le Tiec, A. M. Papon, C. Jaussard, and M. Bruel, Mater. Sci. Eng., B 46, 349 (1997).

${ }^{10}$ Q.-Y. Tong, T.-H. Lee, L.-J. Huang, Y.-L. Chao, and U. Gösele, Electron. Lett. 34, 407 (1998)

${ }^{11}$ K. D. Hobart and F. J. Kub, Electron. Lett. 35, 675 (1999).

${ }^{12}$ Y. Zheng, P. D. Moran, Z. F. Guan, S. S. Lau, D. M. Hansen, T. F. Kuech, T. E. Haynes, T. Hoechbauer, and M. Nastasi, J. Electron. Mater. 29, 916 (2000).

${ }^{13}$ J. M. Zahler, C.-G. Ahn, S. Zaghi, H. A. Atwater, C. Chu, and P. Iles, Thin Solid Films 403-404, 558 (2002).

${ }^{14}$ T. Izuhara, M. Levy, and R. M. Osgood, Jr., Appl. Phys. Lett. 76, 1261 (2000).
${ }^{15}$ F. J. Kub, K. D. Hobart, J. M. Pond, and S. W. Kirchoefer, Electron. Lett. 35, 477 (1999).

${ }^{16}$ B. Aspar, H. Moriceau, E. Jalaguier, C. Lagahe, A. Soubie, B. Biasse, A. M. Papon, A. Claverie, J. Grisolia, G. Benassayag, F. Letertre, O. Rayssac, T. Barge, C. Maleville, and B. Ghyselen, J. Electron. Mater. 30, 834 (2001).

${ }^{17}$ B. Aspar, M. Bruel, H. Moriceau, C. Maleville, T. Poumeyrol, A. M. Papon, A. Claverie, G. Benassayag, A. J. Auberton-Herve, and T. Barge, Microelectron. Eng. 36, 233 (1997).

${ }^{18}$ M. Bruel, Nucl. Instrum. Methods Phys. Res. B 108, 313 (1996).

${ }^{19}$ V. P. Popov, I. E. Tyschenko, L. N. Safronov, O. V. Naumova, I. V. Antonova, A. K. Gutakovsky, and A. B. Talochkin, Thin Solid Films 403-404, 500 (2002).

${ }^{20}$ G. A. Kachurin, S. G. Yanovskaya, M.-O. Ruault, A. K. Gutakovskii, K. S. Zhuravlev, O. Kaitasov and H. Bernas, Semiconductors 34, 965 (2000).

${ }^{21}$ X. Weng, S. J. Clarke, W. Ye, S. Kumar, R. S. Goldman, A. Daniel, R. Clarke, J. Holt, J. Sipowska, A. Francis, and V. Rotberg, J. Appl. Phys. 92, 4012 (2002).

${ }^{22}$ X. Weng, R. S. Goldman, V. Rotberg, N. Bataiev, and L. J. Brillson, Appl. Phys. Lett. 85, 2774 (2004).

${ }^{23}$ X. Weng, W. Ye, R. S. Goldman, and J. C. Mabon, J. Vac. Sci. Technol. B 22, 989 (2004).

${ }^{24}$ A. W. Wood, X. Weng, Y. Q. Wang, and R. S. Goldman, Appl. Phys. Lett. 99, 093108 (2011)

${ }^{25}$ R. R. Collino, B. B. Dick, F. Naab, Y. Q. Wang, M. D. Thouless, and R. S. Goldman, Appl. Phys. Lett. 95, 111912 (2009).

${ }^{26}$ H. W. Ro, K. Char, E.-C. Jeon, H.-J. Kim, D. Kwon, H.-J. Lee, J.-K. Lee, H.-W. Rhee, C. L. Soles, and D. Y. Yoon, Adv. Mater. 19, 705 (2007).

${ }^{27}$ J. Mayer, L. A. Giannuzzi, T. Kamino, and J. Michael, MRS Bull. 32, 400 (2007).

${ }^{28}$ M. Alexe, V. Dragoi, M. Reiche, and U. Gösele, Electron Lett. 36, 677 (2000).

${ }^{29}$ O. Moutanabbir and U. Gösele, Annu. Rev. Mater. Res. 40, 469 (2010).

${ }^{30}$ Since the in-plane wafer dimensions typically scale with wafer thickness, $\mathcal{G}$ is expected to be implicitly dependent on the wafer diameter.

${ }^{31}$ Z. Suo and J. W. Hutchinson, Int. J. Fracture 43, 1 (1990).

${ }^{32}$ Filmtronics, Inc., Butler, PA, http://www.filmtronics.com

${ }^{33}$ E. Jalaguier, B. Aspar, S. Pocas, J. F. Michaud, M. Zussy, A. M. Papon, and M. Bruel, Electron. Lett. 34, 408 (1998).

${ }^{34}$ J. F. Ziegler, J. P. Biersack, and U. Littmark, The Stopping and Range of Ions in Matter (Pergamon, New York, 1985). 